\title{
Research on Construction Quality Management of Civil Engineering for Highway Traffic
}

\author{
Wenguang Xie \\ Guiyang Water Resources and Transportation Development Investment Group Co., Ltd., Guiyang Guizhou, \\ 550003, China
}

Keywords: Highway traffic, Civil engineering, Construction quality, Management.

\begin{abstract}
With rapid development of social economy over recent years, China has speeded up modernization construction, and highway traffic engineering has increased gradually in everywhere. Construction quality receives extensive attention all the time. Civil engineering is an important component of highway traffic engineering. The construction quality plays a significant role in the whole quality. In view of this, this paper starts from the early construction stage, under-construction stage and later construction stage in highway traffic civil engineering and discusses corresponding quality management measures in detail for reference.
\end{abstract}

\section{Introduction}

Highway engineering has direct influence on regional economic development, people's travelling and living quality. Thus, China pays high attention to highway traffic construction in the process of actively promoting modernization construction. However, China has a vast territory. Each region needs to face different geological conditions and environmental factors in the process of highway construction. Thus, there are many factors influencing construction quality. In such case, relevant construction enterprises must start from actual construction needs of highway engineering and environmental features, and make relevant quality management measures so as to improve fund utilization rate and guarantee construction quality. This paper overall discusses construction quality management measures of highway traffic civil engineering, in the hope of laying certain foundation for overall development of relevant fields.

\section{Quality management measures before civil engineering construction for highway traffic}

\subsection{To make a scientific construction quality plan}

Before civil engineering construction for highway traffic, relevant construction enterprises must first overall grasp the actual situations of construction site. Thus, enterprises should make appoint professional technical personnel and budget management personnel to comprehensively analyze and study technical process, quality standards, contract contents and quality control measures through cooperation and communication with each department. Based on this, targeted quality control and management plan should be made [1]. In this process, the features of civil engineering construction links should be deeply analyzed, and construction quality control should be planned and specified clearly. Besides, it is required to overall educate workers of civil construction department, improve their quality awareness, make them understand the quality responsibility they undertake and make sure each worker can improve civil construction quality through their efforts. Thus, civil construction workers should take active part in discussion meeting about civil construction quality plan. In the process of participating in making quality control plan, construction workers should cognize the importance of civil construction quality control, clearly know their quality control duties, propose precious suggestions based on their experience and lay a good foundation for improving comprehensiveness and scientificity of quality control plan of highway traffic civil engineering. The quality control plan made on this basis can more effectively guide civil construction, promote 
construction efficiency, guarantee construction quality and avoid fund waste. Finally, construction enterprises must distribute quality control plan to each construction worker. The leaders of construction department should be responsible for explaining quality control plan for workers.

\subsection{To implement level-to-level management mode and responsibility system}

To ensure overall implementation of quality control plan, civil construction department should first have a comprehensive understanding of civil engineering, and divide the engineering into multiple stages and contents. Meanwhile, civil construction department should start from the whole civil engineering, make quality management and control measures for each construction link and make sure the level-to-level management mode and responsibility system are implemented. In addition, civil construction department should overall grasp skills, advantages and features of construction workers, rationally assign the positions, enhance human resource utilization rate, make job contents for workers and make sure they profoundly cognize the contents of level-to-level management, strictly abide by construction standards, apply construction technology and ensure construction quality in routine construction ${ }^{[2]}$.

Meanwhile, it is required to make sure engineering quality control department can give full play to supervision and management functions in civil construction, enhance on-site supervision and inspection force, discover the behaviors violating civil construction provisions and forbid them, improve construction efficiency and ensure construction quality through cooperation and supervision.

\subsection{To enhance communication among construction workers}

Civil construction for highway traffic is composed of multiple links. The connection degree of each link has direct influence on the whole quality ${ }^{[3]}$. human factor is a key factor influencing civil construction quality, so it is also deemed as the emphasis in civil construction quality management. In such case, relevant quality management personnel should establish close contact with construction workers, enhance communication, improve quality awareness and safety education of construction workers, and conduct regular or irregular quality inspection so as to fundamentally ensure civil construction quality.

To achieve this goal, civil construction management personnel and grass-roots construction workers should closely contact, fully communicate with construction workers, grasp their needs and difficulties in life and work, and improve their satisfaction through psychological counseling and material help so that they can more actively cooperate with leaders in quality supervision and management, improve service awareness, safety awareness and quality awareness and finally lay a solid foundation for promoting civil construction quality ${ }^{[4]}$.

\section{Quality control measures in civil construction for highway traffic}

\subsection{To strictly implement fine quality management scheme}

Firstly, civil construction party should start from actual conditions of engineering to make a detailed construction scheme which should not just plan the construction scope and contents in detail, but also describe key construction part and key technology, while quality control emergency measure is one of the important contents. The fine management scheme made on this basis can be instructive, promote smooth implementation and improve construction efficiency on the basis of ensuring civil construction quality.

Secondly, technical disclosure should be carried out efficiently. Civil construction department should overall sum up the quality problems in traditional civil construction for highway traffic, and targeted quality control measures, start from actual conditions of the engineering and analyze the specific technical contents.

Thirdly, construction should be carried out in strict accordance with the design scheme. The rational application of construction procedure and construction technology have direct influence on civil construction quality. So, in order to improve construction quality fundamentally, the design 
scheme should be followed strictly in practical construction, and construction technology should be rationally applied. Meanwhile, the key points of quality control should be specially noticed ${ }^{[5]}$. For example, separation phenomenon may easily occur in concrete material transportation, so it is required to carry out rational stirring and vibration, grasp the transportation time, install and disassemble the template reasonably and pay high attention to concrete maintenance and construction in the later period. As long as the above key quality control contents are grasped, the whole construction quality can improve.

\subsection{To lay emphasis on construction technology management}

Civil construction quality is directly influenced by construction technology. If the technology is not applied rationally, a strong impact on the whole quality will be caused. Thus, it is required to start from the following links in construction technology management.

Firstly, to enhance engineering surveying. Measurement precision must be ensured in civil construction. Multiple advanced technologies should be comprehensively applied to control the precision of civil construction. Repeated measurement and calibration should be done to provide basis for civil engineering design plan, effectively guarantee construction quality and efficiency and finally achieve win-win of economic and social benefits. Therefore, measuring personnel should own strong professional technical capability, and flexibly apply various measuring techniques. Meanwhile, they should have the spirit of bearing hardships and standing hard work, go to the civil construction site and overall measure. More importantly, they should possess initiative spirit, boldly try various advanced measuring techniques and lay a solid foundation for more efficient completion of measurement.

Secondly, design drawings should be checked strictly. In civil construction process, construction workers must start from actual on-site environment, check scientificity and rationality of construction design drawings, and analyze authenticity of design documents and content comprehensiveness to make sure design drawings can efficiently guide civil construction.

\subsection{Strict quality control for key processes}

There are many factors influencing civil construction quality. Construction workers must grasp the key construction links. Construction quality control measurements for foundation pit excavation and bored pile are analyzed as follows.

Firstly, quality control for foundation pit excavation. Foundation pit excavation has direct influence on civil construction quality. Construction workers should rationally set well-point dewatering of the tube well to make sure soil transportation, loading and unloading as well as machine operation can proceed smoothly in civil construction. Meanwhile, earthwork in remote distance should be moved to the operating scope of the excavator by a small loader in the process of foundation pit excavation. Machinery and manpower should be overall applied to excavate earthwork below $6.0 \mathrm{~m}$. Besides, the tower crane should be applied.

Secondly, construction quality control for bored pile. Usually, mechanical hole making is a major way to construct the bored pile. In practical construction, different machines should be applied as required. Usually, underwater concrete pile-forming is a basic construction method. casing pipe drilling machine, rotary drilling machine and percussion drilling machine may be rationally applied for hole forming according to construction features so as to lay a good foundation for construction quality.

\section{Quality control measures after civil construction}

\subsection{Scientific implementation of detail treatment}

After the completion of civil construction, detail treatment should be enhanced to ensure construction quality, and protection should be enhanced for the completed works. In detail treatment, it is required to focus on such aspects as different construction material handover location, examination of construction technique application effect, connection of sub-works. For example, it is 
required to notice whether the specification and quality of embedded iron piece and preformed hole conform to construction requirements and national quality standards. In construction process, the quality of these details may be easily ignored. So, in the later-period quality control, details must be overall checked. Design drawings and standard requirements of civil engineering should be combined to overall analyze the quality of each construction link. Besides, the workers with strong technical ability and rich experience should be appointed to enhance quality inspection. Once quality problem is found, corresponding technical measures should be taken immediately.

\subsection{Efficient implementation of final acceptance of civil engineering}

Civil engineering is a basic link of highway engineering construction, so it is crucial to enhance quality control for this link. It is imperative to carry out completion acceptance. So, relevant departments should carry out completion acceptance at once after the completion of civil construction. Other construction work can be implemented on the basis of making sure there is no quality problem and technical defect. After the completion of engineering construction, completion acceptance should be implemented. In the completion acceptance, relevant workers should deeply study the site construction and the construction situation of each link, and combine the design drawings for comparison to achieve overall assessment and inspection of civil engineering quality and make sure the construction status is consistent with the provisions in the contract. Meanwhile, test evaluation measures should be taken to improve the inspection force of civil engineering safety and usability. Only when there is no quality problem can other links be constructed. Once quality problem is found, overall research should be carried out with the construction party and management layer, and relevant technical measures should be taken to make up for the defects to fundamentally ensure safety of highway traffic engineering use.

\section{Conclusions}

In conclusion, highway engineering is one of key components of social foundation engineering. It not just provides great convenience for people and also makes important contributions to regional economic construction. However, civil construction link has to confront different geological conditions and construction environments in highway traffic engineering construction. There are many factors influencing the quality of civil construction. To improve the quality, it is required to start from early stage, middle stager and later stage of civil construction, and implement full-process quality control idea and system to ensure the quality of highway traffic engineering and lay a good foundation for creating more social and economic benefits.

\section{References}

[1] Wu Dexing, Li Weiping, Gao Xiang et al., Design Practice of Ventilation Civil Engineering Structure of Highway Extra-Long Tunnel in Zhejiang, Highway, 2016(8):287-292.

[2] Liu Xiaoxia, Cui Jin, Liu Jia at al., On Design Essentials of Highway Ultralimit Detection System in Shanxi, Highway, 2017(1):222-227.

[3] Zhang Xinfeng, On Civil Construction Quality Control for Highway Traffic, Urban Construction Theory Research (Electronic Version), 2015(16):1071-1072.

[4] Wang Zengli, Wang Min, Yang Xun et al., Civil Engineering Design of Highway Service Area and Parking Area in Hilly Area, Urban Construction Theory Research (Electronic Version), 2016(15):4958-4958.

[5] Zhang Xunlei, Analysis on Arrangement of Electromechanical Outfield Equipment and Corresponding Civil Engineering Construction for Highway, Science \& Technology Information, 2015(23): 150,159. 